\title{
Corrigendum: The Influence of the Stimulus Design on the Harmonic Components of the Steady-State Visual Evoked Potential
}

\author{
Benjamin Solf*, Stefan Schramm, Maren-Christina Blum and Sascha Klee \\ Institute for Biomedical Engineering and Informatics, Technische Universität IImenau, IImenau, Germany
}

Keywords: steady-state visual evoked potentials, ssVEP, flicker stimulation, harmonic components, stimulus eccentricity, ocular stray light

\section{A Corrigendum on}

The Influence of the Stimulus Design on the Harmonic Components of the Steady-State Visual Evoked Potential

by Solf, B., Schramm, S., Blum, M.-C., and Klee, S. (2020). Front. Hum. Neurosci. 14:343. doi: $10.3389 /$ fnhum.2020.00343

\section{OPEN ACCESS}

Edited and reviewed by:

Shozo Tobimatsu,

Kyushu University, Japan

*Correspondence:

Benjamin Solf

benjamin.solf@tu-ilmenau.de

Specialty section:

This article was submitted to Brain Imaging and Stimulation,

a section of the journal

Frontiers in Human Neuroscience

Received: 20 December 2020 Accepted: 30 December 2020

Published: 26 January 2021

Citation:

Solf B, Schramm S, Blum M-C and Klee $S$ (2021) Corrigendum: The Influence of the Stimulus Design on the Harmonic Components of the

Steady-State Visual Evoked Potential.

Front. Hum. Neurosci. 14:644304.

doi: 10.3389/fnhum.2020.644304
In the original article, there was an inaccurate statement. In the introduction, we cited studies analyzing the effect of stimulation parameters on the harmonic components of ssVEP. Thereby, we made the statement that the studies did not analyze the occurrence of the main response at the harmonic components. After a cited author pointed out that the responses at higher harmonic components were analyzed in their study, we revised our statement.

A correction has been made to Introduction, Paragraph 4. The corrected paragraph is shown below:

The effect of the stimulation parameters on the harmonic components of ssVEPs was analyzed in some studies. For example, Johansson and Jakobsson (2000) found significant higher amplitudes at high temporal frequencies in normal subjects than in stereo-blind subjects. Gulbinaite et al. (2019) analyzed the effect of attention on the amplitudes of the harmonic components for stimulation frequencies within the range of $3-80 \mathrm{~Hz}$ and found an opposite effect of attention on the individual resonance frequencies in the alpha and gamma band.

The authors apologize for this error and state that this does not change the scientific conclusions of the article in any way. The original article has been updated.

\section{REFERENCES}

Gulbinaite, R., Roozendaal, D. H., and VanRullen, R. (2019). Attention differentially modulates the amplitude of resonance frequencies in the visual cortex. NeuroImage 203:116146. doi: 10.1016/j.neuroimage.2019.116146

Johansson, B., and Jakobsson, P. (2000). Fourier analysis of steady-state visual evoked potentials in subjects with normal and defective stereo vision. Doc. Ophthalmol. 101, 233-246.

Copyright (c) 2021 Solf, Schramm, Blum and Klee. This is an open-access article distributed under the terms of the Creative Commons Attribution License (CC BY). The use, distribution or reproduction in other forums is permitted, provided the original author(s) and the copyright owner(s) are credited and that the original publication in this journal is cited, in accordance with accepted academic practice. No use, distribution or reproduction is permitted which does not comply with these terms. 